\title{
ENTRE A SOCIEDADE CIVIL E A SOCIEDADE POLÍTICA
}

\author{
PARTICIPATORY INSTITUTIONS IN DEMOCRATIC BRAZIL \\ de Leonardo Avritzer. Baltimore: The Johns Hopkins University Press, 2009. 205 Pp.
}

WAGNER DE MELO ROMÃo

[1] Princeton/Oxford: Princeton University Press, 2002.
[2] Todas as passagens do livro citadas foram traduzidas pelo autor.

[3] Provavelmente, esta incorporação da sociedade política como um componente analítico no mesmo nível da sociedade civil tenha se devido, de um lado, a outros trabalhos sobre o $O P$ que enfatizaram a centralidade das iniciativas partidárias para o sucesso (ou fracasso) de inúmeras experiências. De outro lado, Avritzer passa a reconhecer a multiplicidade de situações relativas à "vontade política" com relação ao OP no interior mesmo do Partido dos Trabalhadores e outros partidos de esquerda.
Participatory institutions in democratic Brazil é a obra mais importante de Leonardo Avritzer desde a publicação de Democracy and the public space in Latin America1. O autor rediscute e amplia a análise sobre experiências de orçamento participativo (OP) nas cidades de Porto Alegre, Belo Horizonte e São Paulo e também apresenta estudos sobre mais duas "instituições participativas" — os conselhos de saúde e os processos de formulação dos planos diretores urbanísticos nestas cidades, e também em Salvador.

Avritzer reelabora o que tem sido seu principal desafio teórico desde os anos de 1990: as aproximações entre sociedade civil e sociedade política, e a incorporação de práticas originárias da sociedade civil pelas instituições políticas, em novos "desenhos institucionais" participativos com poder de deliberação sobre políticas públicas. O autor propõe-se a desenvolver uma "teoria das instituições participativas" (p.4) e reconhece que "os partidos políticos e a sociedade política permanecem pouco teorizados na maior parte da literatura sobre participação, por causa do caráter elitista da literatura ou das concepções anti-sistêmicas da teoria dos movimentos sociais" ${ }^{2}$. Isto seria uma lacuna na literatura, sobretudo no contexto brasileiro, "em que o Partido dos Trabalhadores (PT) mostrou o caminho ao introduzir arranjos participativos, a conexão entre partidos políticose sociedade civil na implementação de modelos de participação vem a ser uma variável-chave - mas que não é esclarecida pela teoria" (p.7). Assim, a principal diferença deste livro para seus trabalhos anteriores é a incorporação da dimensão político-partidária à análise.

Avritzer busca formular sua teoria sobre as instituições participativas relacionando-a com três elementos principais: a sociedade civil, a sociedade política e o desenho institucional3. Inicialmente, o autor 
retoma a tese já presente em seus trabalhos anteriores: as mudanças na sociedade civil brasileira - explicadas, sobretudo, pelo avanço do associativismo em grandes cidades como Porto Alegre, São Paulo e Belo Horizonte a partir de meados dos anos de 1970 - teriam atuado fortemente para a democratização do país, em uma perspectiva autonomista ante o Estado autoritário, distinta de uma cultura política anterior, centrada na aproximação clientelista e subalterna ao aparelho estatal. Entretanto, o autor identifica algumas peculiaridades locais. Em Belo Horizonte e, principalmente, em Porto Alegre, indica maior autonomia em face do Estado e dos partidos políticos, na comparação com São Paulo e Salvador. Além disso, os movimentos sociais de Belo Horizonte e Porto Alegre seriam mais "generalistas" no que diz respeito ao acesso a bens públicos, enquanto os de São Paulo e Salvador teriam objetivos mais localizados em torno da saúde e educação, em São Paulo, e do movimento cultural, em Salvador. Tais diferenças seriam fatores de maior ou menor sucesso na incorporação das "instituições participativas" ao sistema político formal.

Em seguida, o autor direciona suas observações às mudanças ocorridas na sociedade política brasileira e latino-americana nos anos de 1980 e 1990 .É então que começa a ser incorporada à análise a dimensão partidária, pouco explorada nos textos anteriores em virtude da avaliação sobre a centralidade da sociedade civil nos processos de democratização no Brasil e na América Latina, e também pela visão de que o Estado seria refratário aos impulsos democratizantes advindos da esfera societária. Neste livro, ao contrário, Avritzer enfatiza o modo como a sociedade política, os partidos políticos de esquerda e, especificamente, o Partido dos Trabalhadores teriam atuado para a formalização do que chama de "instituições participativas", incorporando demandas sobre participação presentes em suas origens "externas" às instituições políticas formais:

A sociedade política, no interior das instituições participativas, relaciona concepções de participação originárias dos atores da sociedade civil. Nesse sentido, reforça concepções gerais de participação que estão na raiz da formação dos partidos políticos de massas e de esquerda. [...] O PT, no Brasil, desempenha exatamente este papel de relacionar ideias de participação presentes em suas origens com atores da sociedade civil que demandam participação. Na maior parte dos casos de participação analisados neste livro, a iniciativa foi tomada por atores da sociedade política (p.10).

Esta nova demarcação teórica, dada pela incorporação dos partidos políticos à análise, dá-se de modo bastante específico: 
[4] É interessante perceber como o autor, assim, vincula diretamente os movimentos sociais que demandam políticas públicas de todas as ordens à ação estrita da Igreja Católica.
Afirmo que a distinção entre partidos de massa e partidos eleitorais ainda é válida. Além disso, argumento que o lado identitário da formação do partido continua a ser relevante no debate sobre partidos politicos de massa. Demonstro que um partido de massas com ligações externas ao sistema político éo veículo ideal para trazer demandas participativas ao Estado (p.13).

Assim, o modo pelo qual Avritzer incorpora a sociedade política na análise se dá pelo viés da sociedade civil, uma vez que o PTé visto como um partido de origem nela e portador de suas demandas participativas. As mudanças na sociedade política - em suma, o aparecimento do PT - são derivadas das mudanças ocorridas na sociedade civil: o PT, herdeiro direto do associativismo revigorado nos anos de 1970 e 1980 , teria atuado como cabeça de ponte da participação popular no sistema político, facilitando a inserção de práticas democratizantes da sociedade civil no Estado.

Dessa forma, assim como no caso da sociedade civil, a caracterização do PT elaborada por Avritzer se dá na chave da autonomia: "o projeto político do PT nasce das demandas por autonomia em relação ao Estado feitas pelo novo sindicalismo e pela Igreja Católica" (p.47). No caso do "novo sindicalismo", tratar-se-ia de autonomia diante da tutela do controle do Estado sobre as organizações sindicais. No caso da Igreja Católica,Avritzer indica que "autonomia significou a habilidade dos atores sociais de demandar bens públicos - terra, serviços sociais, saúde, ou melhorias urbanas, como pavimentação ou saneamento independentemente do Estado" (p.47)4. Ao "novo sindicalismo" e à Igreja Católica, o autor agrega o que chama de new left, parcela da esquerda que critica os comunistas, sem que se demore em investigar suas características e o modo como teria se agregado às duas outras "forças de coalizão".

Além disso, também como um componente identitário do PT, figuram a crítica ao clientelismo e a adoção da democracia participativa. Estes fatores teriam contribuído para que o PT tivesse inovado institucionalmente ao introduzir formas de participação no orçamento, na saúde e na política urbana.

É a partir desta caracterização do papel do PT na sustentação das "instituições participativas" que o autor introduz o que parece ser o principal - embora modesto - ganho analítico de Participatory institutions in democratic Brazil. Avritzer argumenta que, para que sejam investigadas as causas dos sucessos e dos fracassos das políticas participativas das diversas administrações petistas, devem ser conhecidas as seções locais do PT, sobretudo, quanto à relação entre identidade e estratégia no nível local. E avalia que o PT, como todo partido político de esquerda e de massas de perfil social-democrata, teria passado pelo dilema de manter sua identidade sociopolítica, 
construída sobre o princípio da autonomia dos movimentos sociais dos quais seria originário, e ao mesmo tempo tornar-se competitivo no sistema político - a dimensão estratégica. As variações desses dois pólos (identidade e estratégia) deveriam ser consideradas no âmbito local (municipal e/ou estadual). Deste conjunto de fatores originou-se maior ou menor "vontade política" da seção local do PT e de seus governos municipais para com as "instituições participativas" (p.5oss).

Cabe no momento indicar o terceiro elemento analítico utilizado por Avritzer no livro. Ele propõe um olhar sobre as "mudanças no desenho institucional" (pp. 62-80), apresentando um "modelo dinâmico e interativo de desenho participativo":

O modelo dinâmico e interativo também compreende que o sucesso do desenho participativo não é causado pelo desenho em si; antes, cada sucesso éo resultado não antecipado de interações entre atores da sociedade política e da sociedade civil que levam ao desmantelamento das velhas regras e fixam as novas (p.64).

Este é fundamento do movimento teórico pelo qual o autor incorpora a sociedade política como um ator propositivo de instituições participativas, e não apenas resistente a elas. A partir da premissa do "desenho institucional e interativo", são apresentadas três possibilidades de instituições participativas - o orçamento participativo, os conselhos de saúde e os processos de aprovação dos planos diretores municipais. Com base nelas, o autor constrói tipos ideais de desenho institucional, respectivamente os chamados bottom-up designs (desenhos "de baixo para cima"), os power-sharing designs (desenhos de compartilhamento de poder) e os ratification designs (desenhos de ratificação). Esses modelos terão maior ou menor possibilidade de sucesso de acordo com o modo em que se dá o encontro entre sociedade civil e sociedade política no contexto local.Assim, por meio da análise sobre como se comporta cada design em cada uma das quatro cidades estudadas, o autor pretende construir quadros comparativos que o levem a uma "teoria das instituições participativas".

O livro denota um relativo deslocamento nas teses anteriores de Avritzer, sobretudo quanto ao orçamento participativo. De fato, era insustentável a pouca importância teórica dada ao contexto político-partidário das localidades, sobretudo aquele relativo aos posicionamentos do PT local e mesmo às disputas no interior do partido. Embora o tema não estivesse totalmente ausente em seus textos anteriores, o autor não havia ainda tratado do papel central dos governos - e dos partidos que os sustentam - na proposição e no controle dos processos de orçamento participativo. Ou seja, não havia ainda 
[5] Avritzer, Leonardo, Recamán, Marisol e Venturi, Gustavo. "O associativismo na cidade de São Paulo". In: Avritzer, L. (org.). A participação em São Paulo. São Paulo: Editora da Unesp, 2004, pp. 11-57.

[6] Avritzer. "O orçamento participativo: as experiências de Porto Alegre e Belo Horizonte". In: Dagnino, Evelina (org.). Sociedade civil e espaços públicos no Brasil. São Paulo: Paz e Terra, 2002, pp. 17-45; Ibidem, “O orçamento participativo e a teoria democrática: um balanço crítico". In: Avritzer e Navarro, Z. (orgs.). A inovação democrática no Brasil: o orçamento participativo. São Paulo: Cortez, 2003, pp. 13-6o. estabelecido como preocupação teórica a natureza das relações entre os partidos políticos e a sociedade civil que ajudam a explicar a configuração das instâncias participativas, considerando a propensão do PT local a estimular e fortalecer as instituições participativas. Avritzer pouco se debruçara sobre o problema dos padrões de comportamento e composição local dos partidos que ajudam a explicar as variações de "vontade política" nas várias experiências de orçamento participativo nos governos petistas ou não-petistas.

Este passo analítico teve que ser dado principalmente pelo relativo fracasso da experiência do OP de São Paulo. Anteriormente saudado como "potencializador da dinâmica participativa na cidade"5 - a postura adotada pelo autor com relação a esse caso se torna mais crítica neste livro. Assim, a incorporação de São Paulo ao seu rol de cidades estudadas (em textos anteriores ele se respaldava nas experiências "positivas" de Porto Alegre e Belo Horizonte ${ }^{6}$ ) — traz a necessidade de explicar por que, em uma cidade com movimentos sociais tradicionalmente vigorosos, a experiência de OP não teria sido satisfatória na capital paulista.

Os oito anos de malufismo (1992-2000) entre a primeira e a segunda administração petista em São Paulo são indicados como perniciosos para a estruturação de instituições participativas na cidade. Isto teria se dado não só em relação ao OP, mas também aos conselhos de saúde e à elaboração de seu plano diretor urbanístico. Entretanto, o que é central como opção analítica é a verificação das divisões internas no PT paulistano sobre as prioridades dadas à participação popular, já presentes no governo de Luiza Erundina e acentuadas no governo de Marta Suplicy.

É fundamental ao argumento de Avritzer indicar o PT como um partido pró-participação. Os casos em que isso não se configura são ora explicados pelas fissuras internas ao partido - entre setores mais ou menos afeitos às instituições participativas —, ora indicados como "concessões" ao sistema político formal para que o partido não "perca votos", como na justificativa pela "opção" do governo de Marta Suplicy em não privilegiar o OP como política de gestão, pela necessidade eleitoral que o teria levado a realizar acordos com a direita malufista na Câmara de Vereadores (p.113).

Para Avritzer, quando há harmonia intrapartidária nas seções locais do PT, as chances de que o OP vingue são maiores. Este argumento vale tanto para o caso negativo - São Paulo - em que não teria havido acordo no interior do partido sobre a dimensão a ser dada às políticas participativas, como para o caso positivo - Porto Alegre -, em que teria havido um "pacto" entre as principais facções para que as disputas internas não atrapalhassem o projeto político maior na cidade: 
Em Porto Alegre, Olivio Dutra tomou posse com o apoio de todos os grupos internos ao PT, liderando um pacto segundo o qual cada facção local do PT iria indicar o prefeito nas eleições subsequentes. Tarso Genro seguiu Dutra, e Pont seguiu Genro, mostrando como este pacto no âmbito das lideranças produziu uma durável hegemonia do PT na cidade (p.58).

Afirmações de tal natureza indicam os limites da análise de Avritzer e demonstram as insuficiências da compreensão apresentada pelo autor quanto aos padrões internos da competição político-partidária. É sabido que as disputas entre as forças políticas internas do PT de Porto Alegre - e gaúcho de maneira geral — nos anos de 1990 talvez tenham sido ainda mais conflagradas do que as do PT paulistano. Segundo Filomena7, de 1993 a 1999, estabeleceu-se uma aliança entre as tendências Articulação de Esquerda e Democracia Socialista (DS), adversárias do PT Amplo (grupo liderado por Tarso Genro). Tanto é que, ao contrário do que aponta Avritzer, em 1996 houve prévias entre Raul Pont (DS) e José Fortunati (PT Amplo) para a escolha do candidato a prefeito, vencidas pelo primeiro. Fortunati, então, torna-se vice de Pont. Já em 2000 , mesmo com a vigência da possibilidade da reeleição, as novas prévias envolvem Pont, Fortunati e Genro, que as venceu. Estas situações e os muitos casos de desfiliações de figuras locais proeminentes - como o próprio Fortunati e, antes dele, Antonio Hohlfeldt, que fora o primeiro vereador do partido em Porto Alegre, eleito em $1982^{8}$ - indicam que o ambiente interno do PT gaúcho pouco diferia do habitual em outras seções do partido. Ou seja, as disputas por indicações a cargos majoritários deram-se em geral na base do voto e da quantidade de delegados que cada candidato ou facção conseguia arregimentar. Tal aritmética, da mesma forma, era a base para a nomeação de mais ou menos correligionários aos cargos no governo ou no partido 9 . O prestigiado OP porto-alegrense, sem dúvi$\mathrm{d}$, tornou-se também um anexo a esta disputa, pois se tornou um espaço político estratégico de fortalecimento dos grupos internos ${ }^{10}$.

É também interessante verificar como Avritzer trata de um caso negativo de orçamento participativo, o de São Paulo na gestão de Marta Suplicy (PT). Para o autor, a explicação para o fracasso se deve aos seguintes fatores, combinados:1) o núcleo de assessores mais próximos de Suplicy seria cético em relação à participação, e teria deixado o comando do OP aos setores esquerdistas do PT na capital paulista, com pouco poder político no interior do partido e da gestão; 2) a opção de governabilidade executada pelo governo fora a incorporação de setores conservadores e malufistas à maioria governista, sobretudo por meio das nomeações de subprefeitos. Isto teria dificultado o OP em subprefeituras dominadas por membros de partidos não comprometidos com a participação.
[7] Filomena, César L. O agonismo nas relações sociais do partido, dos espaços públicos da sociedade civile do sistema administrativo estatal: a experiência da Administração Popular em Porto Alegre. Porto Alegre: dissertação de mestrado, Programa de Pós-graduação em Ciências Sociais da PUC-RS, 2006.

\begin{abstract}
[8] Antonio Hohlfeldt retira-se do PT em 1993, filiando-se ao PSDB, e José Fortunati, em 2001, filiando-se ao PDT.Ambos continuaram como figuras de proa na política no Rio Grande do Sul, sendo que Hohlfeldt foi vice-governador do estado (no governo de Germano Rigotto - PMDB) e José Fortunati é, atualmente, o prefeito de Porto Alegre (beneficiado pela renúncia de José Fogaça - PMDB).
\end{abstract}

[9] O que não quer dizer que tenha sido o único critério para nomeações.

[10] Baierle, Sergio. "OP ao termidor?”. In: Verle, João e Brunet, Luciano (orgs.). Construindo um mundo novo: avaliação da experiência do orçamento participativo em Porto Alegre Brasil. Porto Alegre: Guayí, 2002, p. 132-64. Cf. Filomena, op. cit. 
[11] Cf. Avritzer, Democracy and the public space in Latin America, op. cit.; "O orçamento participativo: as experiências de Porto Alegre e Belo Horizonte", op. cit.; "O orçamento participativo e a teoria democrática: um balanço crítico", op. cit.

[12] Avritzer, Democracy and the public space in Latin America, op. cit. pp. 152-3.

[13] Segundo survey utilizado como referência por Avritzer, em 2003, $69 \%$ dos participantes do OP de São Paulo pertenceriam a associações voluntárias.
Embora certamente tais fatores possam explicar parcialmente a pouca relevância do OP na elaboração do orçamento e na priorização de políticas públicas na cidade de São Paulo, não explicam o fato de o OP de São Paulo ter apresentado, nos quatro anos em que esteve em vigor, um crescente aumento na participação, que variou crescentemente de 34 mil a 82 mil pessoas, entre 2001 e 2004 (p.101).

Em outros trabalhos, relativos aos casos de Porto Alegre e Belo Horizonte, Avritzer vinculou a participação à credibilidade do processo perante a população. Em suma, as regras do orçamento participativo seriam efetivas e as deliberações quanto à priorização de obras e serviços seriam cumpridas pelos governos ${ }^{11}$. No caso de Porto Alegre, o autor liga a baixa participação em algumas regiões com "menor tradição associativa" a dúvidas sobre a capacidade do processo em promover a execução de obras públicas. Sugere, então, que a existência anterior de práticas de participação da sociedade civil predetermina a efetividade do orçamento participativo. No caso de Belo Horizonte, os altos e baixos níveis de participação que se apresentam ano após ano são ligados também a dúvidas dos participantes quanto à efetividade e à continuidade do orçamento participativo. Em seu estudo sobre esta cidade, o autor relaciona tais dúvidas com a incerteza sobre se o candidato do PT ganharia as eleições em 1996 e se, depois, o prefeito do PSB daria a mesma prioridade ao OP12. Todas essas elucubrações, de fraca consistência empírica, servem ao autor para o reforço de suas premissas sobre a capacidade da população em participar de "modo racional".

Em São Paulo, mesmo considerando que o OP "sempre levantou fortes dúvidas sobre o quão deliberativas seriam suas decisões" (p. 100), os números oficiais utilizados pelo autor demonstram que houve sempre um acréscimo dos níveis de participação, mesmo considerando que o OP paulistano teria privilegiado os setores mais organizados da população' (p. 102), em tese, os mais esclarecidos sobre eventuais manipulações da prefeitura e/ou sua incapacidade em entregar as obras prometidas.

Tais inconsistências analíticas sobre a participação no OP e a limitação em se consideraros partidos políticos e governos apenas com relação à "vontade política" para se implementar ou não propostas participativas fazem com que o livro pouco avance na análise sobre o que realmente pauta a dinâmica política das experiências de OP e, de resto, das "instituições participativas". A incorporação da sociedade política em sua argumentação é restringida por seu arcabouço teórico anterior, vinculado ao protagonismo da sociedade civil na proposição de processos participativos. Esta visão permanece em Participatory institutions in democratic Brazil, impedindo-o de avançar significativamente na incorporação à análise das dinâmicas próprias da sociedade política. 
Artigos e livros publicados ao longo desta década ${ }^{14}$ têm contribuído para que se forme a seguinte tese: as "instituições participativas" são freqüentadas principalmente por agentes (indivíduos e grupos) situados nas franjas da "sociedade política", em torno (ou mesmo no interior) dos partidos políticos. Esta visão é reforçada à medida que se sobe na escala de proximidade com a sociedade política, ou seja, no caso das experiências de orçamento participativo, de maneira crescente desde as reuniões de bairro até os "conselhos do orçamento participativo", que deliberam sobre a proposta orçamentária a ser apresentada à Câmara de Vereadores e têm maior capacidade institucional de interagir com o poder municipal. A proximidade com as esferas estatais invariavelmente é utilizada pelos conselheiros para um melhor posicionamento pessoal (ou de grupo) no interior da dinâmica político-partidária-eleitoral de cada bairro e da cidade.

Diante disso, é preciso que o referencial analítico sobre os processos participativos induzidos pelos poderes públicos seja remodelado. Deve-se caracterizar, afinal, quem acorre aos conselhos e, mais do que qualificar e mensurar a relação dos conselheiros com organizações da sociedade civil, verificar qual o nível de relação destes com a sociedade política, tanto nas instituições (governos, partidos), como nos processos típicos das disputas realizadas na sociedade política, sobretudo as campanhas eleitorais. Afinal, quem é a "sociedade civil" que participa dessas experiências? E em que medida seus "representantes" podem ser considerados como tal, uma vez que, numa visão mais acurada, mantêm vínculos tão fortes com a sociedade política?

Este veio de análise não poderia ser trilhado por Avritzer, pois põe à prova suas teses originais sobre uma "sociedade civil" que demandaria espaços de participação e atuaria neles de maneira autônoma pela democratização do Estado. O argumento do livro, de que "o elemento analítico relevante é como sociedade civil e sociedade política interagem" (p.165), mantém intacto o espírito de seus textos desde A moralidade da democracia ${ }^{15}$. É notável como, em Participatory institutions in democratic Brazil - embora avance na observação do contexto local das relações internas dos governos e partidos - , sociedade civil e sociedade política permanecem como elementos estanques. Pouco se diz sobre o quanto a dimensão substantiva da sociedade civil — tal como conceituada por Avritzer - , em vez de se afirmar, pode ser diminuída nos orçamentos participativos e nas outras instituições políticas.
[14] Navarro, Zander. "Orçamento participativo de Porto Alegre (19892002): um conciso comentário crítico". In:Avritzer e Navarro op. cit., pp. 89-128; Wampler, Brian. "Instituições, associações e interesses no orçamento participativo de São Paulo". In:Avritzer (org.).A participação em São Paulo, op. cit., pp.371-407; Gurza Lavalle, Adrian, Houtzager, Peter e Achrya, Arnab. "Lugares e atores da democracia: arranjos institucionais participativos e sociedade civil em São Paulo". In: Coelho, Vera Schattan e Nobre, Marcos (orgs.). Participação e deliberação: teoria democrática e experiências institucionais no Brasil contemporâneo. São Paulo: Editora 34, 2004, pp. 343-67; Baiocchi, Gianpaolo. Militants and citizens: the politics of participatory democracy in Porto Alegre. StanfordCA: Stanford University Press, 2005; Coelho, Vera Schattan e Favareto, Arilson. "Dilemas da participação e desenvolvimento territorial". In: Democracia, sociedade civil e participação. Chapecó: Argos, 2007, pp. 97-126; Wampler, Brian. Participatory budgeting in Brazil: contestation, cooperation, and accountability. University Park, PA: The Pennsylvania State University Press, 2007.

[15] Avritzer. A moralidade da democracia: ensaios em teoria habermasiana e teoria democrática. São Paulo/Belo Horizonte: Perspectiva/Editora da UFMG, 1996. 